$\begin{array}{ll}\text { Revue d'Alsace } & \text { Revue d'Alsace } \\ & 133 \mid 2007 \\ & \text { Histoire régionale Landesgeschichte en France et en } \\ & \text { Allemagne } 1950 / 2000\end{array}$

\title{
Eugène Kurtz (1921-2006)
}

Jean-Marie Holderbach

\section{(2) OpenEdition}

Journals

Édition électronique

URL : http://journals.openedition.org/alsace/1509

DOI : $10.4000 /$ alsace.1509

ISSN : 2260-2941

Éditeur

Fédération des Sociétés d'Histoire et d'Archéologie d'Alsace

Édition imprimée

Date de publication : 1 octobre 2007

Pagination : 517-518

ISSN : 0181-0448

\section{Référence électronique}

Jean-Marie Holderbach, « Eugène Kurtz (1921-2006) », Revue d'Alsace [En ligne], 133 | 2007, mis en

ligne le 10 novembre 2011, consulté le 19 avril 2019. URL : http://journals.openedition.org/

alsace/1509; DOI : 10.4000/alsace.1509 


\section{Eugène Kurtz (1921-2006)}

Eugène Kurtz nous a quittés. Passionné d'histoire et d'archéologie, il était membre de la Société d'histoire de Saverne, de celle des Quatre Cantons dont il a favorisé la création et de la Société pour la Conservation des Monuments Historiques d'Alsace.

De 1980 à 1990, Eugène Kurtz, alors jeune retraité a œuvré au sein du comité directeur de la Fédération des sociétés d'histoire et d'archéologie d'Alsace. Il y tint la comptabilité et participa très activement au recensement des petits monuments ruraux et des bornes anciennes, notamment celles ayant marqué les frontières de l'Alsace.

Au cours de ses recensements le long de la frontière allemande, il a aussi tissé des relations amicales, fraternelles comme il disait, avec des historiens de la rive droite du Rhin. En l'honorant de la qualité de membre d'honneur de leur association Historischer Verein für Mittelbaden, ceux-ci ont reconnu en lui l'homme ouvert, généreux, soucieux de donner un sens concret et humain à la réconciliation franco-allemande. Des sentiments qui d'ailleurs l'avaient animé dès le lendemain de la dernière guerre.

Son souvenir à la Fédération est resté très vivace, notamment pour son dévouement, son enthousiasme, sa sympathie et son esprit de camaraderie dont il a imprégné toutes ses actions.

Archéologue infatigable, Eugène menait régulièrement des prospections notamment dans le Ried, mais surtout dans les Vosges, autour de Walscheid, sur les hauteurs de Garrebourg, de Hultehouse ou du Wasserwald. Il n'y a sans doute pas une parcelle des forêts de Dabo dont il n’a foulé le sol.

Toutes ses recherches assidues et méthodiques ont abouti à quelques découvertes remarquables dont il ne se vantait guère, mais qui lui ont valu une reconnaissance des mi-

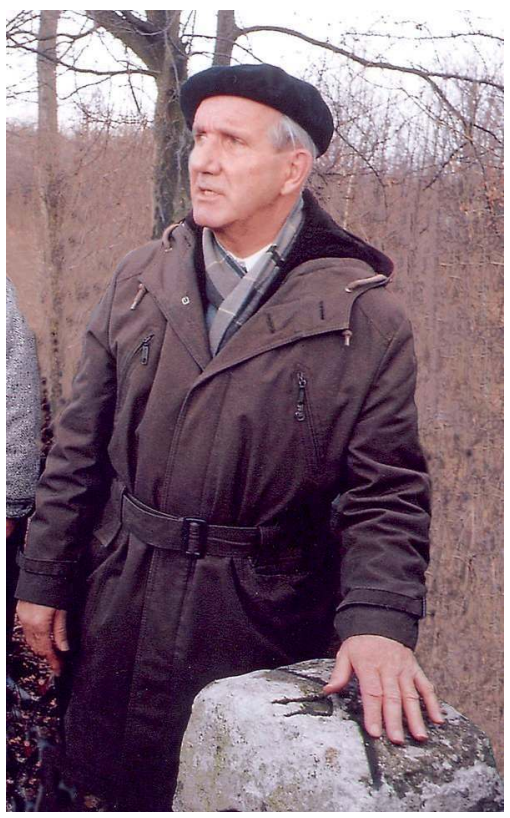
lieux scientifiques spécialisés. Rappelons simplement qu'en 1976 il avait redécouvert les vestiges du château du Daubenschlagfelsen pour lequel il a obtenu la première autorisation de fouille (1979). Plus récemment, il avait découvert sur les pentes du Ludwigsberg (vallée de la Zorn Jaune) un remarquable bas-relief de Mercure aujourd'hui exposé au Musée du Pays de Sarrebourg.

Ses longues randonnées archéologiques, que j'ai souvent partagées avec lui, étaient aussi propices à des échanges, des discussions, à l'évocation de ses souvenirs - c'est ainsi qu'est venue l'idée de rédiger ses mémoires.

Syndicaliste, membre dirigeant de la Jeunesse ouvrière chrétienne (JOC), Eugène Kurtz a eu une jeunesse mouvementée. En 1942, ayant tenté de rejoindre Londres, il 
a été arrêté sur la ligne de démarcation, interné au camp de Schirmeck puis incorporé de force et envoyé sur le front russe. Il réussit cependant à s'évader et à rejoindre l'Ambassade de France à Moscou où il a été affecté à la Mission militaire française dirigée par le Général Petit. Dans son ouvrage, La guerre malgré moi, Eugène Kurtz raconte cette partie tourmentée, aventureuse, comme il disait, de sa vie en s'appuyant sur son abondante correspondance de l'époque, heureusement conservée.

Eugène Kurtz était un homme généreux, sensible et ouvert. Au cours de nos randonnées, il s'arrêtait parfois pour s'émerveiller devant un paysage ensoleillé, un rocher façonné par le vent, un bouquet d'épilobes ou un parterre de pervenches. Dans tous les charmes de la nature Eugène voyait la main de Dieu. Dans cette nature qu'il aimait tant, il cheminait d'un pas souvent alerte, écartant de sa canne les fougères et examinant avec soins chaque pierre de la forêt.

S’il fallait caractériser en deux mots Eugène Kurtz, sans hésiter, les termes amitié et fraternité viendraient à l'esprit de tous ceux qui l'ont connu. Pour lui l'amitié était une valeur cardinale et la fraternité entre les hommes son idéal qu'il poursuivait inlassablement, nourri et guidé par l'enseignement du Christ.

A maintes occasions Eugène m’a aussi parlé de sa fin. Solidement ancré dans sa foi chrétienne, il ne craignait pas de quitter la vie. Pour lui, la vie terrestre n'était qu'une étape. Il ajoutait aussitôt, avec confiance et conviction : " Non, non ! tu verras, ce n'est pas une fin, nous nous reverrons tous!»

Alors voilà Eugène, ta famille et tes amis sont réunis pour te dire au revoir, avec la même confiance.

Nombreux articles dans Jeunesse ouvrière d'Alsace (JOC) en 1946-1947, dans le Travailleur d'Alsace et de Lorraine (CFTC) en 1947-1948, dans la Vie populaire du Bas-Rhin (APF) en 1963 ; Le Daubenschlagfelsen et son château, SHASE, 1980/1, p. 17-21 ; Randonnée de la croix du Langenthal au pont du Maibachel, Les Vosges 1981/1, p. 8-14 ; L'affaire du Général Petit, DNA (Strasbourg) du 31.1.1982 ; Un établissement gallo-romain à Nordhouse, Annuaire de la Société d'histoire des quatre cantons, 1983, p. 13-23 ; La forêt de Corrière (au ban de Wisches), Essor, n 127, 1985, p. 25-28 ; Carte archéologique de Nordhouse, Annuaire de la Société d'histoire des quatre cantons, 1985, p. 41-47 ; Les bornes Noblat et Tulla, ibidem, 1988, p. 119-137 ; Le drame des deux Raon, 1992 (une version condensée a paru dans Essor, n 153-155, décembre 1991-juin 1992). E. Descamps, Militer, Paris, 1971, p. 52 ; Ch. Dillinger, 50 ans de JOC, Equipes sociales d'Alsace, Strasbourg, 1979, p. 71, 161-162 ; M. Hildenbrand, Jahresbericht des Historischen Vereins für Mittelbaden 1990/1991, Die Ortenau, 1991, p. 22-23, ill.

Iconographie : J.-M. Holderbach, Les bornes de la mémoire, Saisons d'Alsace, n 111, 1991, p. 166.

Allocution prononcée lors des funérailles Jean-Marie Holderbach 